\section{Architectural Development of Inflorescence in Hydrangea macrophylla cv. Hermann Dienemann}

\author{
Gilles Galopin ${ }^{1,2}$, Sandrine Codarin, Jean-Daniel Viemont, \\ and Philippe Morel
}

UMR SAGAH A 462, Sciences Agronomiques Appliquées à l'Horticulture. INRA-INH-Université d'Angers. 42 rue Georges Morel, B.P. 57, 49071 Beaucouzé, France

Additional index words. Hydrangea macrophylla, inflorescence organogenesis, phenological stages

\begin{abstract}
Architectural development of inflorescence in Hydrangea macrophylla cv. Hermann Dienemann was observed using scanning electron microscopy. The study of inflorescence morphogenesis shows that the architecture is of the dichasial type. The first two orders of branching are initiated from a dichasial branching without floral differentiation. The following orders present floral differentiation. They determine the formation of small units through the development of composite dichasium into biparous and uniparous cymes. This research makes it possible to establish a schematic representation of the first phases of inflorescence development and to define early stages of inflorescence morphogenesis.
\end{abstract}

The Hydrangea genus consists of shrubs and vines with complex and polymorphous inflorescences. They are corymbiform in $H$. macrophylla and $H$. petiolaris and panicular in H. quercifolia and H. paniculata (Bertrand, 1992). In Hydrangea macrophylla, the inflorescence form has evolved with the application of varietal selection for horticultural purposes. Inflorescences were originally composed of many fertile florets in the center and of several sterile flower clusters on the periphery. Hydrangea macrophylla 'Hermann Dienemann' has globular inflorescences with a majority of decorative sterile florets.

Hydrangea macrophylla inflorescences are in the terminal position and composed of several partial inflorescences (Kuhlen, 1956). These partial inflorescences look like thyrses composed of simple inflorescences of the multiparous, biparous, and uniparous cyme types. The reproduction of these different types of organization varies depending on the size of the inflorescence and the floral expression. Wisniewska proposes characterizing this inflorescence as a pleiochasial cyme and not as a corymb (Wisniewska and Zawadzka, 1962). The inflorescence is composed of small fertile florets and sterile florets with large colored sepals. Fertile florets are differentiated as of the second branching order in terminal position. Sterile florets are

Received for publication 23 Mar. 2007. Accepted for publication 24 June 2007.

This work was supported by Florema France Production.

We are grateful to M. Laffaire for his technical assistance and C. Andreazza (Electronic Microscopy Center, Orléans University).

${ }^{1}$ Current address: Institut National d'Horticulture, 2 rue Le Nôtre, 49045 Angers, France.

${ }^{2}$ To whom reprint requests should be addressed; e-mail gilles.galopin@inh.fr differentiated later and are located on the secondary branchings of the dichasium.

Inflorescence development takes place over two growing seasons (Kosugi and Arai, 1960). It begins with the end of lateral growth of the vegetative stem and the formation of a bud (Goi et al., 1992). This period is triggered by fall-like climatic conditions characterized by a decrease in the photoperiod and a drop in temperatures (Bailey, 1989). An initial organogenesis phase ensures the development of the first three branching orders of the inflorescence and the formation of the first fertile florets with differentiation of sepals and petals and the initiation of stamens and carpels (Wisniewska and Zawadzka, 1962). This initial period is interrupted by a dormancy phase during which inflorescence organogenesis is reduced. After dormancy is broken by low winter temperatures, we observe a second organogenesis phase. It is characterized by the continuation of the development of fertile florets and the differentiation of sterile ones. It ends with floral maturity, the growth of inflorescence axes, and the onset of flowering. The organogenesis of inflorescence is characterized by different development stages (Adkins and Dirr, 2003; Litlere and Stromme, 1975). These stages were defined to measure the effect of growing conditions on floral development and to allow us to obtain highquality horticultural plants.

The aim of this work is to study the initial organogenesis phases of Hydrangea macrophylla 'Hermann Dienemann' inflorescence in relation to its architectural development. Research is based on macroscopic and microscopic morphological observations.

\section{Materials and Methods}

Observations were made on Hydrangea macrophylla cv. Hermann Dienemann. The mother microplant technique was used for vegetative multiplication (Galopin et al., 1996) and plants were grown in pots (Galopin and Guérin, 2002). After cuttings were made in April, the plants were kept in a greenhouse until June. They were grown outside from July to October. They were then placed in a cold chamber for 6 weeks at $4{ }^{\circ} \mathrm{C}$ to break dormancy before being subjected to forcing in a greenhouse to promote flowering. Bud observations were made on plants sampled from September to November during which time floral transformation and inflorescence organogenesis occurred. Inflorescence observations were made at the end of forcing. Forcing was carried out in the greenhouse at a temperature of $20^{\circ} \mathrm{C}$ and a relative humidity of $60 \%$.

Three complementary methods were used to observe buds. Observation with a stereomicroscope with a magnification of $8 \times$ to $40 \times$ made it possible to describe phenological stages. Meristems were observed by cryoscanning electric microscopy (SEM). Just before observation, apical buds were separated from the plant axis. Shoot apexes, $\approx 2 \mathrm{~mm}^{3}$ in size, were excised after the foliar primordia protecting the meristem were rapidly removed under a stereomicroscope. Samples were placed in water and observed a few minutes after dissection to avoid excessive dehydration. Samples were prepared in the Polaron LT 7400 (Elexience, France) cryopreparation system for cryo-FESEM. To do this, samples were cryofixed by dipping them into nitrogen slush at $-210^{\circ} \mathrm{C}$. Superficial ice was removed by temporarily raising the temperature to $-70^{\circ} \mathrm{C}$. This preparation makes it possible to stabilize the samples by dehydrating them before observing them in a vacuum. This rapid technique is particularly appropriate for water-rich samples that are likely to fade during traditional preparation. Uncoated samples were observed at $-150{ }^{\circ} \mathrm{C}$ at $1 \mathrm{KV}$. Observations were carried out using cryo-SEM with a Hitachi 4200 (Elexience, France) field emission instrument (Défarge et al., 1999). For histological examination, the meristems were fixed in a $4 \%$ glutaraldehyde solution for $2 \mathrm{~h}$. They were then dehydrated in an ethanol series $(50 \%, 70 \%, 95 \%$, and $100 \%$ ) and embedded in resin. Samples then underwent infiltration in a Technovit $7100^{\circledR}$ (Heraeus Kulzer, Germany) base and inclusion in a hardener. Cross-sections of $7 \mu \mathrm{m}$ were made with an automatic microtome. They were stained with a mixture of toluylene blue and safranin.

\section{Results}

Architectural development of inflorescence in Hydrangea macrophylla cv. Hermann Dienemann. Inflorescence has a complex architectural structure. The proximal structure is composed of two pairs of branches and a terminal axis. The opposite-decussate position of the branches is similar to phyllotaxis of the leafy stem. Although we often observe a concaulescence of the branches, each branch is axiled by a bractiform leaf. This 
structure forms the primary branching of first-order inflorescence (Fig. 1B-C). In second and third orders, first-order branches are in the form of composite dichasium. Bracts are visible in the second order. They are generally absent or present in the form of subulated bracts in the third order. Second and third orders form the secondary branching (Fig. 1D). Subsequent branching orders form distal branching. Small inflorescence units are composed of uniparous, biparous, and multiparous cymes initiated from the dichasial branching. In all of the cases, the apical meristem initiates the formation of a fertile floret. The development of axillary meristems ensures the formation of either axillary branchings or of sterile florets (Fig. 1E-G).

Phenological stages of inflorescence development. Macroscopic observations make it possible to differentiate seven phenological stages that characterize inflorescence development from the vegetative apex to floret differentiation (Fig. 2). Stage 1 characterizes the apex at the vegetative stage. Stage 2 is the first inflorescence stage showing an enlargement and a meristematic dome. Stage
3 appears after the division of the inflorescent meristem into three meristematic domes. Stage 4 presents nine meristematic domes. Stage 5 corresponds to a large number of inflorescent meristematic domes that result in the characteristic globular shape. Stage 6 corresponds to the differentiation of floral primordia. Stage 7 corresponds to the differentiation of floral organs with sepals, petals, and stamens.

Inflorescence development. The use of SEM and histology makes it possible to observe the division of meristematic domes during inflorescence development. Formation of the stem with opposite-decussate phyllotaxis is the result of the plastochronic activity of the vegetative meristem. The activity of the initiating ring is therefore represented by two meristematic sites that periodically shift by $90^{\circ}$ around a central shaft that rhythmically rises as a result of medullary meristem activity (Fig. 3A). The two opposite initial sectors have two meristematic activity phases (regeneration and initiation) separated by a relative rest phase during a period equal to two plastochrones.
The decussate initial sectors are never in the proliferation phase at the same time. The initiating ring and the medullary meristem are highly active with a strong rhythmicity. Under the two layers of tunical cells, the axial apical zone has a low activity level [Fig. $4(1)]$. The transition from the vegetative state to the floral state is characterized by an activation of the entire apical zone. The meristem modifies its form, its size increases, and it takes on a homogeneous cytological appearance and loses its plastochronic functioning [Figs. 3B and 4(2)]. A division process allows the meristematic domes to multiply. We observe an increase in the activity of the axial apical zone, growth of the epidermal layer by anticlinal division, and vacuolation of the medullary meristem [Fig. 4(3)]. The break up of the inflorescence cluster is caused by intercalary divisions of long cells perpendicular to the surface. At the same time, vascularization takes place with the differentiation of procambial strands from new inflorescential meristems. Division is a reiterative process based on an elementary model and constant with a multiplication factor of three
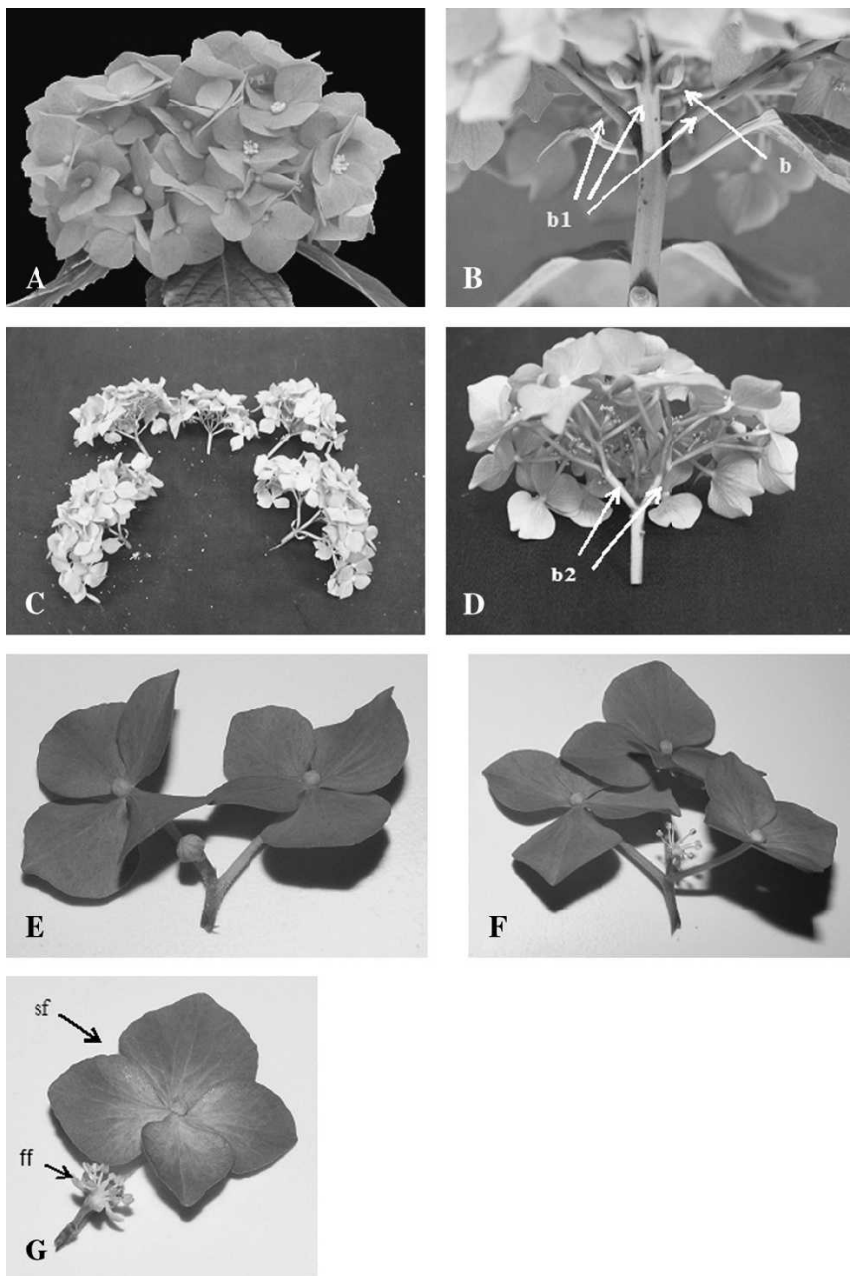

Fig. 1. Inflorescence of Hydrangea macrophylla 'Hermann Dienemann'. (A) Globular inflorescence; (B) inflorescence branching; (C) the five primary branchings; (D) division of a primary branching; (E) uniparous cyme; (F) biparous cyme; $(\mathbf{G})$ multiparous cyme. b1 = first-order branchings; b2 = second-order branchings; $\mathrm{ff}=$ fertile floret; $\mathrm{sf}=$ sterile floret; $\mathrm{b}=$ bracts .
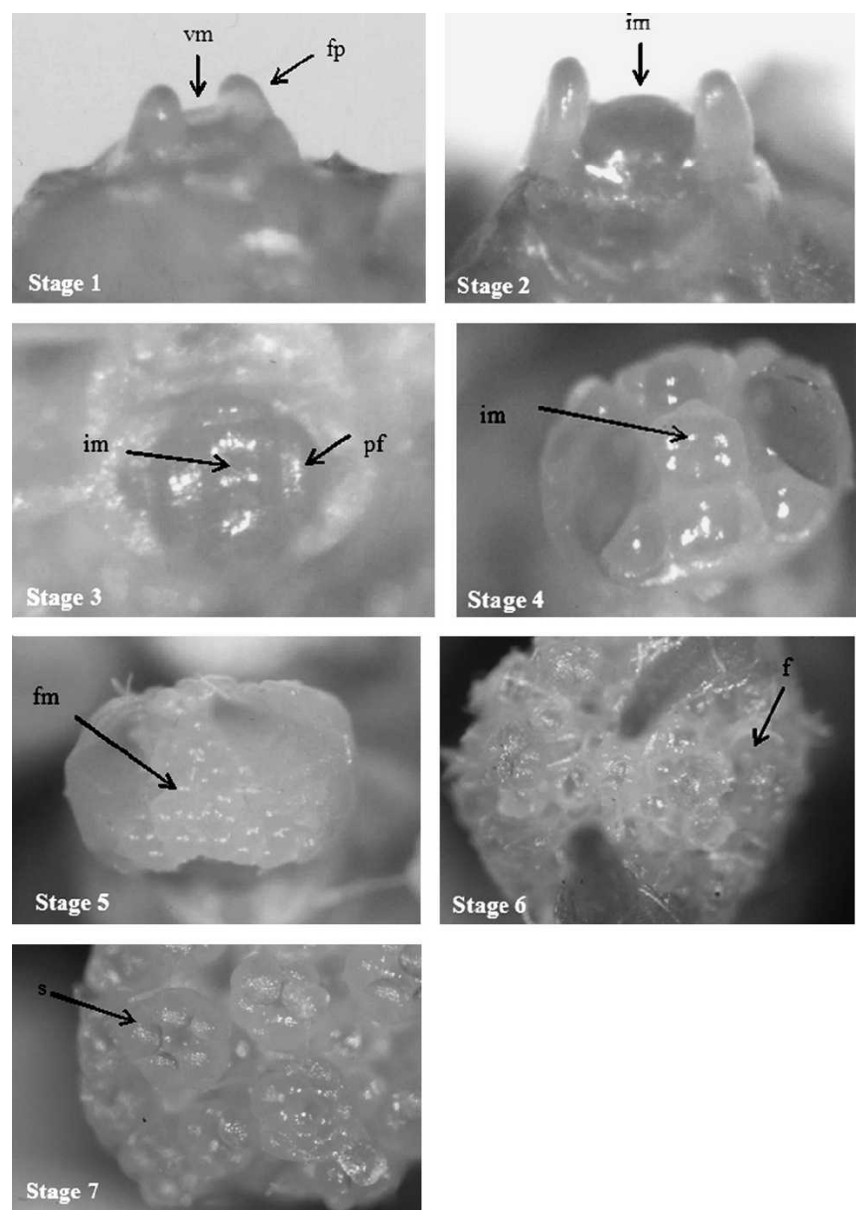

Fig. 2. Floral development stages of Hydrangea macrophylla 'Hermann Dienemann' observed with a stereomicroscope: stage 1; stage 2; stage 3; stage 4 ; stage 5 ; stage 6 ; and stage $7 . \mathrm{vm}=$ vegetative meristem; $\mathrm{im}=$ inflorescential meristem; $\mathrm{fm}=$ floral meristem; $\mathrm{fp}=$ foliar primordia; $\mathrm{f}=$ floret; $\mathrm{s}=$ sepal. 

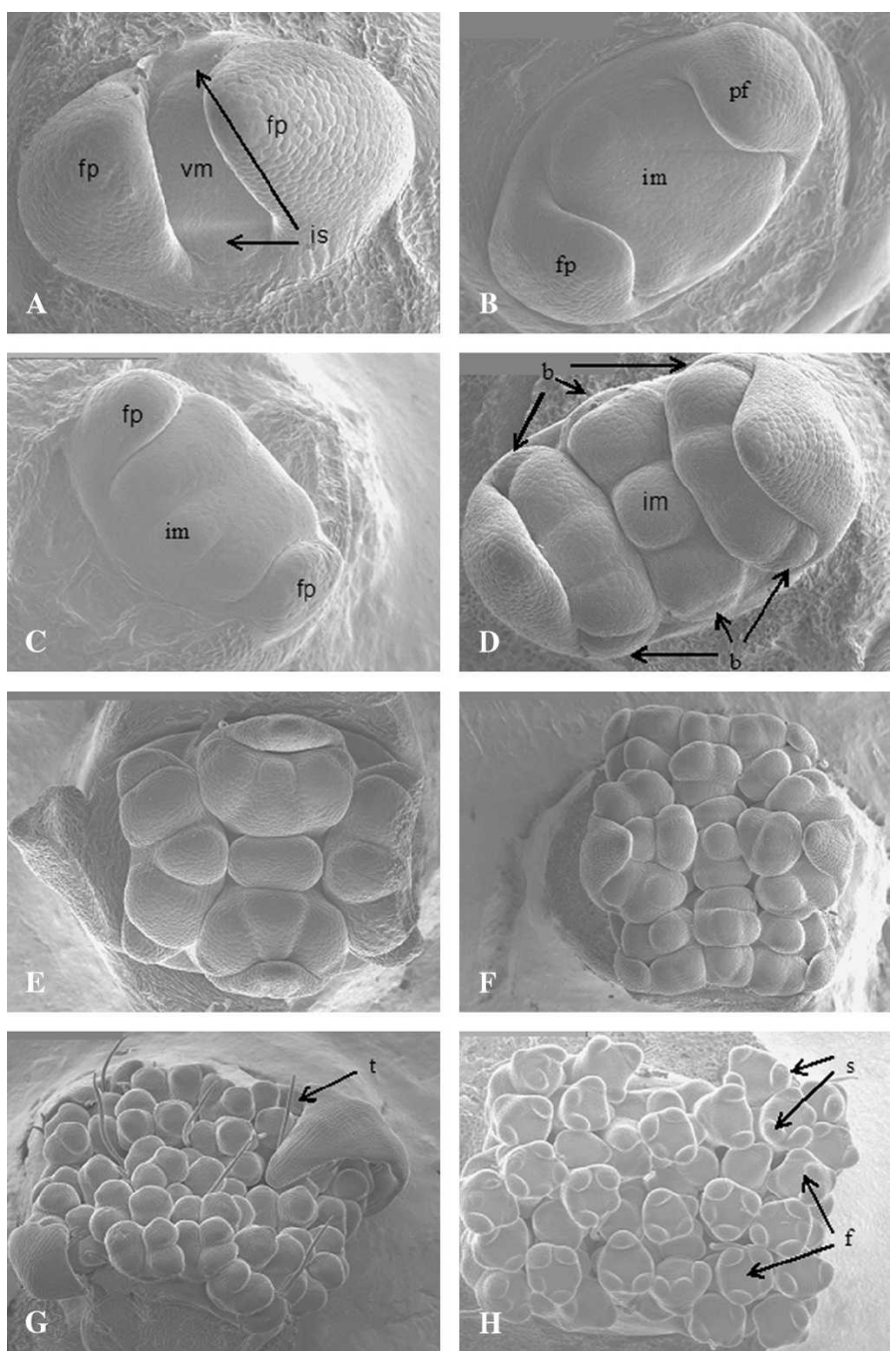

Fig. 3. Meristems of Hydrangea macrophylla 'Hermann Dienemann' observed by cryo-scanning electron microscopy. (A) Stage $1(\times 250)$; (B) stage $2(\times 200)$; (C) stage $3(\times 250)$; (D) stage $4(\times 180)$; (E) stage $5(\times 110)$; (F) stage $5(\times 70)$; (G) stage $6(\times 60)$; (H) stage $7(\times 70)$. vm $=$ vegetative meristem; im $=$ inflorescential meristem; is $=$ initial sectors; $\mathrm{b}=$ bract; $\mathrm{fp}=$ foliar primordia; $\mathrm{f}=$ floret; $\mathrm{s}=$ sepal; $\mathrm{t}=$ trichome.
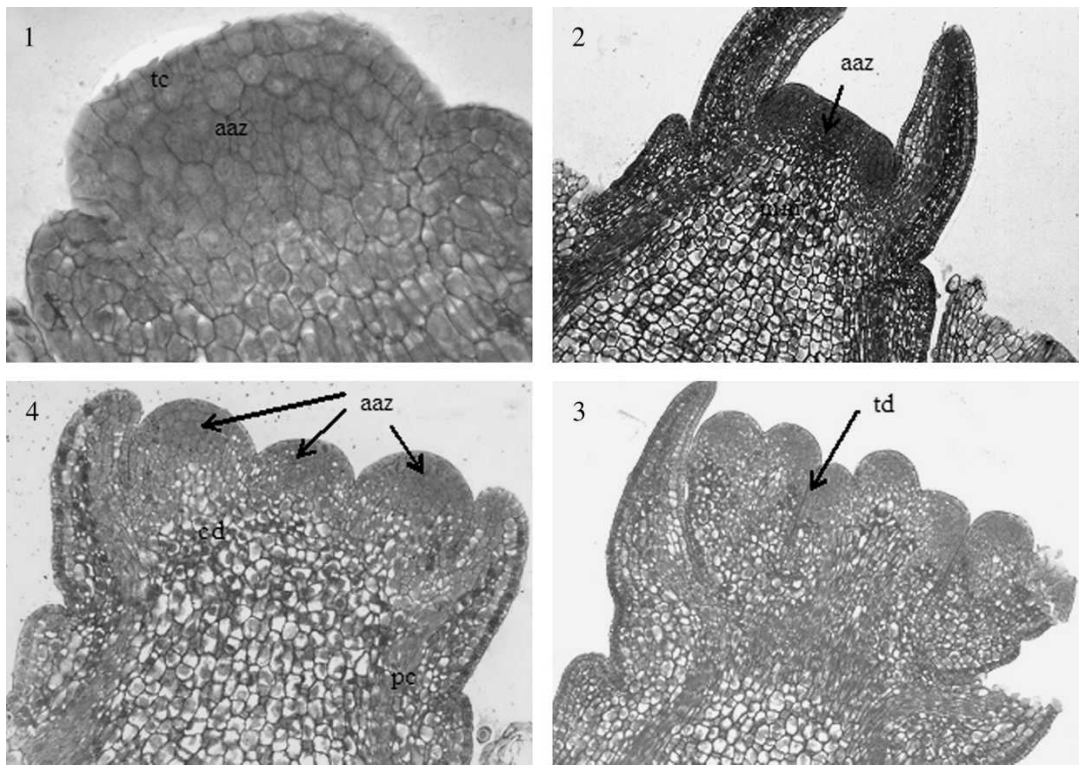

Fig. 4. Histological sections of Hydrangea macrophylla 'Hermann Dienemann' meristems. Division of the inflorescential meristem: (1) vegetative meristem; (2) inflorescential meristem; (3) first division of the meristematic dome; (4) division of inflorescential meristem. tc = tunical cells; aaz = axial apical zone; $\mathrm{mm}=$ medullary meristem; $\mathrm{pc}=$ procambium; $\mathrm{cd}=$ cell differentiation; $\mathrm{td}=$ tangential divisions .
[Fig. 4(4)]. The first division leads to the formation of three meristematic domes parallel to the last two foliar primordia (Fig. 3C). The second division involves the three previously formed domes and leads to the formation of nine domes. At this stage, we can observe the presence of bracts (Fig. 3D). The following division involves the peripheral meristematic domes. The central dome, in the terminal position on the axis, continues the division process but with a delay. This division thus leads to the formation of 13 domes (Fig. 3E). The continuation of these divisions leads to an increasing and exponential number of meristematic domes. Division is always based on the reproduction of the elementary model, and we observe a temporal synchronization of the division process for inflorescence clusters in the opposite position. After the development of a large number of meristematic domes, we can observe the presence of trichomes. These trichomes are unicellular, most often not branched and of epidermal origin (Fig. 3G). Division continues up to the differentiation of flowers in the terminal position (Fig. 3H).

Schematic representation of the first phases of inflorescence development. The architectural structure of inflorescence is very hierarchical. It is based on the proliferation of basic units known as dichasium. On the basis of a schematic representation of the chronology and the localization of meristematic divisions, it is possible to follow the development of inflorescence structure. Three stages can be distinguished. The first phase corresponds to floral transformation by the termination of vegetative meristematic activity and the activation of the inflorescence meristem. (Fig. 5, Phase I). It corresponds to phenological stages 1 and 2 described previously. The second phase corresponds to the formation of five primary branchings. It involves two division cycles (Fig. 5, Phase II) and corresponds to phenological stages 3 and 4 . The third phase is the continuation of inflorescential branches up to the third and fourth order (Fig. 5, Phase III) corresponding to phenological stage 5. At this phase, the schematic representation clearly shows the five primary inflorescential clusters with a lower branching level for the central cluster. The continuation of branchings appears to be less hierarchal because the inflorescence is increasingly large in a volume limited by the foliar organs of the floral bud. It ends in the differentiation of small inflorescence units.

\section{Discussion}

The corymb is a branched structure in which secondary branchings of unequal length are inserted on the axis at different levels and end on approximately the same horizontal plane. Proximal lateral branches are longer than distal lateral branches. The inflorescence of Crataegus monogyna is described as a perfect corymb (Crête, 1962). In Hydrangea macrophylla, the localization of first- and second-order branchings and the globular form of the inflorescence give the 
Phase I

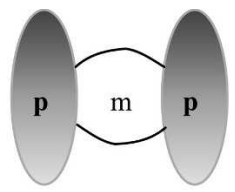

A

B
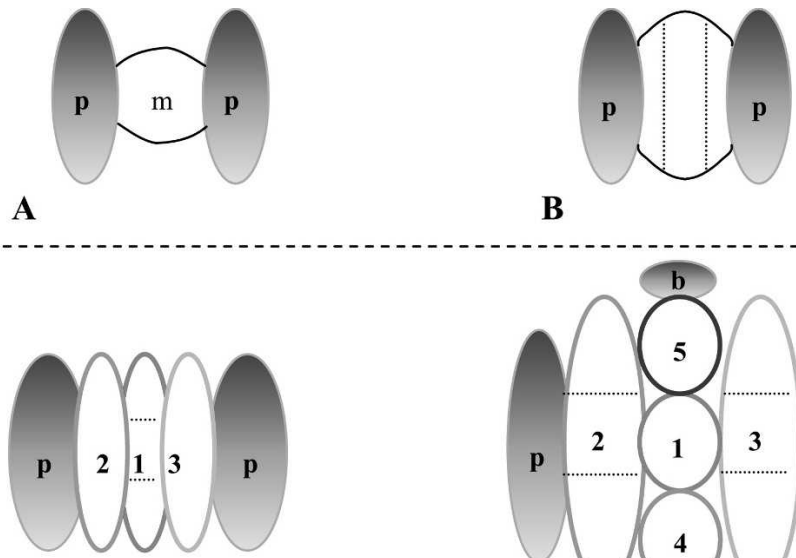

C

D

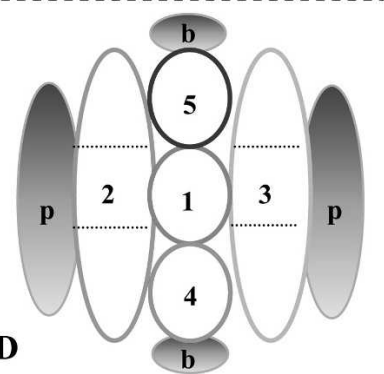

Phase III
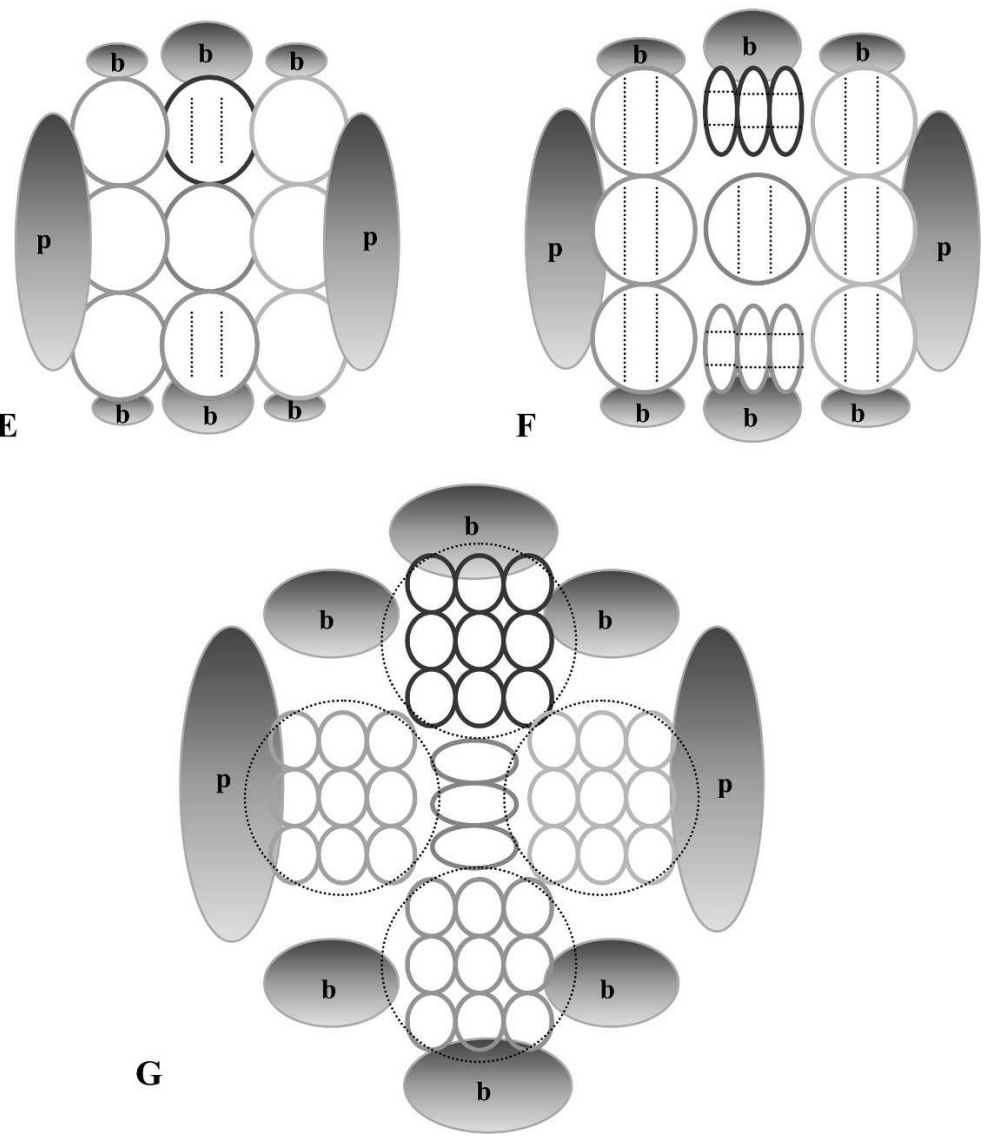

Fig. 5. Schematic representation of the architectural development of inflorescence and meristem division. $\mathrm{p}=$ foliar primordia; $\mathrm{b}=$ bract $\mathrm{m}=$ meristem .

inflorescence the appearance of a corymb. Nevertheless, higher-order branchings are cyme-type dichasium. The study of inflorescence morphogenesis shows that inflorescence architecture is of the dichasial type. In 1955, Lawrence (1955) presented the dichasium as being at the origin of the evolution of different types of inflorescences. With its successive branchings, the dichasium can lead to the formation of a thyrse and the differentiated growth of axes can lead to the formation of a corymb. The floral expression on the primary axis or on secondary axes of the dichasium can also lead to the formation of a composite dichasium or of a biparous or uniparous cyme. In Hydrangea macrophylla, the first two branching orders are initiated from a dichasial branching without flowering and with differentiated axis growth. This structure is related to a corymb (Kuhlen, 1956). Subsequent orders are formed of composite dichasium with the presence of a fertile floret in the terminal position and the branching of lateral axes (Uemachi and Nishio,
2000). These last branching orders are biparous and uniparous cymes without branchings and with differentiation of a fertile floret in the axial position and the differentiation of sterile florets in the lateral position. This inflorescence, described as a corymb of cymes (Bertrand, 1992), is of the dichasial type with differentiated development of the dichasium in inflorescence morphogenesis.

Variations in growing conditions make it possible to modify the size of the inflorescence, the number of fertile and sterile florets, and the flowering date (Morel, 2001; Shank, 1981; Vidalie, 1989). They therefore have an effect on the different inflorescence organogenesis phases described previously. Organogenesis is divided into two periods, before and after dormancy (Bailey, 1989). Artificialization of the breaking of dormancy by placing plants in a cold chamber interrupts the first organogenesis period and can therefore reduce the branching degree of inflorescence. The phenological stages described in seven levels represent markers of the state of the inflorescent bud to determine the date when plants are to be placed in a cold chamber. Stage 5 is recommended at this time. On the basis of the schematic representation of the architectural development of inflorescence, it is possible to ensure the initiation of flowering (Phase I), the formation of proximal branchings (Phase II), and a branching of small inflorescence units (Phase III).

\section{Literature Cited}

Adkins, J.A. and M.A. Dirr. 2003. Remontant flowering potential of ten Hydrangea macrophylla (Thunb.) Ser. cultivars. HortScience 38:1337-1340.

Bailey, D.A. 1989. Hydrangea production. Timber Press Growers handbook series. In: Armitage, A.M. (ed.). Portland, Oregon. Vol. 3. 91p.

Bertrand, H. 1992. Identification of Hydrangea macrophylla Ser. cultivars. Acta Hort. 320:209-212.

Crête, P. 1962. Précis de botanique. Tome I: Morphologie et reproduction des plantes vasculaires, systématique des cryptogames vasculaires et des gymnospermes. Masson et Cie, Paris.

Défarge, C., Issa O.M., and Trichet J. 1999. Apports du cryo-microscope électronique à balayage à émission de champ à l'étude des matières organiques et des relations organominérales naturelles. Application aux croûtes microbiotiques des sols. Compte-rendu de l'Académie des Sciences de Paris, Sciences de la Terre et des planetes 328:591-597.

Galopin, G., F. Beaujard, and M. Gendraud. 1996. Intensive production of juvenile cuttings by mother microplant culture in Hydrangea macrophylla 'Leuchtfeuer'. Can. J. Bot. 74:561567.

Galopin, G. and V. Guérin. 2002. Biologie de la plante entière, p. 63-72. In: Guérin, V. (ed.). Hydrangea: Acquisitions nouvelles et applications. INRA éditions, Paris.

Goi, M., Z. Guo, and M. Tanaka. 1992. Morphological studies on the bud formation in Hydrangea macrophylla Ser. F. Hortensia Rehd. 'Miss Hepbarn'. Technical Bulletin of Faculty of Agriculture, Kagawa University. 44:55-63. 
Kosugi, K. and H. Arai. 1960. Study on the flower bud differentiation and development in some ornamental trees and shrubs. VII. On the date of flower bud differentiation and flower bud development in Hydrangea macrophylla. Technical Bulletin of Faculty of Agriculture, Kagawa University. 12:78-83.

Kuhlen, H. 1956. Zur morphologie und anatomie der gattung Hydrangea, p. 36-47. In: Die Hortensien. Verlag Deutsche Gärtnerbörse, Aachen.
Lawrence, G.H.M. 1955. Taxonomy of vascular plants. Macmillan, New York.

Litlere, B. and E. Stromme. 1975. The in influence of temperature, day length and light intensity on flowering in Hydrangea macrophylla. Acta Hort. 51:285-298.

Morel, P. 2001. growth control of Hydrangea macrophylla through water restriction. Acta Hort. 548:51-58.

Shank, J.B. 1981. Out of season forcing of Hydrangea macrophylla. HortScience 16:83-84.
Uemachi, T. and T. Nishio. 2000. Inflorescence development in Hydrangea macrophylla. Acta Hort. 515:265-271.

Vidalie, H. 1989. Behaviour of miniature Hydrangea macrophylla (quality and duration of forcing) after various cold treatments before forcing. Acta Hort. 261:355-358.

Wisniewska, E. and Z. Zawadzka. 1962. Przebieg Ksztaltowania sie Kwiatostanu u Hydrangea macrophylla Ser. Cv. Altona. Acta Agrobotanica. XI:157-165. 